\title{
Parametric Optimization of Single Cylinder Diesel Engine Fueled with Karanja Biodiesel \& Diesel Blend for Brake Thermal Efficiency using Taguchi method
}

\author{
Jinalben M Prajapati ${ }^{1}$, Pragna R Patel ${ }^{2}$, Dr. Tushar M Patel ${ }^{3}$ \\ ${ }^{1}$ M.E. Scholar, Mechanical Engineering Department, LDRP-ITR, Gandhinagar, India. \\ ${ }^{2}$ Assistant Professor, Mechanical Engineering Department, LDRP-ITR, Gandhinagar, India. \\ ${ }^{3}$ Professor, Mechanical Engineering Department, LDRP-ITR, Gandhinagar, India.
}

\begin{abstract}
An experimental study has been carried out for Karanja biodiesel and it's blend with diesel used in single cylinder diesel engine. Biodiesel is obtained from oil by Trans-esterification process. In this study, the effects of parameters` i.e. blend ratio, compression ratio, injection pressure and load are taken as variable for optimization. As the experiment required simultaneously optimization of four parameters with three levels, Taguchi method of optimization is used in this experiment. The results of the Taguchi experiment identifies that $0 \%$ blend ratio, 18 compression ratio, injection pressure 160 bar and engine load $9 \mathrm{~kg}$ are optimum parameter setting for highest brake thermal efficiency. Engine performance is mostly influenced by engine load and is least influenced by injection pressure. Confirmation experiment was done using optimum combination showed that brake thermal efficiency was found by experiment is closer to the predicated value.
\end{abstract}

Keywords: Karanja biodiesel, Trans-esterification, Taguchi method

\section{Introduction}

Consumption of the fossil fuels reserves and increasing cost of the petrol and diesel are the big troubles of today's world. Two approaches are provide for this problem solution, first produce substitute fuel or diesel engine and second one is increases the combustion efficiency. Biodiesel fuel production have been established various process such as emulsification, pyrolysis and trans-esterification. The source used for the Biodiesel production is the eco-friendly and emit less emission. Several cooking (Caster, Sesame, Groundnut, Palm, Soybean, Corn, etc.), and non-cooking oils (Jatropha, Karanja, Neem, Mahua etc.) and fats, agricultural waste, plastic waste, tire waste, etc. Various optimization techniques used for engine study are Taguchi method, RSM method, nonlinear regression method, and genetic algorithm. DOE with upgrading of control parameters to obtain the 'best' outcomes is achieved in the Taguchi Method. The Taguchi method develops orthogonal arrays from theory of DOE to examine a more number of variables with a less number of trials. Optimum design of input parameters were recognized that can increase mechanical efficiency and brake thermal efficiency. It has been studied the effects of biodiesel blend, injection pressure, compression ratio and load on Brake thermal efficiency. The Taguchi method develops L9 orthogonal arrays, in this design 4 parameter with 3 levels. Total number of experiment runs will be 9 . In this paper optimization study of variable compression ratio diesel engine fueled with Karanja biodiesel and its blend using the Taguchi method.

\section{Literature Review}

NATARAJ et al. (2005) studied on adjusting diesel engine parameters for low emissions using Taguchi technique. Measurement of exhaust emissions of the enhanced engine showed that carbon monoxide, hydrocarbon and burn emissions remain decreasing [1]. HULWAN et al. (2010) studied on properties improvement and performance advantage of diesel-ethanol-biodiesel blends with higher percentage of ethanol in a multi cylinder IDI diesel engine. The BSFC increased for the blends at all the loads compared to diesel fuel. The BTE increase for the blends is due to the rise in the peak pressure resulting from a better combustion process, which tends to increase the conversion of heat into work [2]. KARNWAL et al. (2010) studied Taguchi method and GRA for optimization of diesel engine act parameters. It was found that diesel engine when operated on $30 \%$ biodiesel blend, low CR of 14, high IP 250 bar and $20^{\circ}$ has given optimum engine performance which is defined thru maximum thermal efficiency, minimum BSEC, least EGT and lowest emissions [3]. JOSHI et al. (2012) studied on adjusting diesel engine parameters for better mechanical efficiency using Taguchi technique. They concluded that Taguchi is best method for control parameter and also concluded that optimum parameter set for highest mechanical efficiency is 5\% blend ratio, 20\% engine load, 180 bar injection pressure, engine performance most influenced by load end least influenced by injection pressure [4]. SIVARAMAKRISHNAN et al. (2012) investigated Karanja biodiesel used in place of straight diesel fuel with Taguchi multiple regression analysis and optimization performance. Result found that the emissions CO, HC 
emission reduced while NOx emissions increase [5]. DHAR et al. (2013) studied effect of KOME mixture with diesel on particulate emissions from a transportation engine. It was found that without modification of engine, $100 \%$ Karanja biodiesel showed highest total particulate number emissions at all engine operating conditions. Other biodiesel blends displayed quite lower or comparable total particulate number emissions compare to diesel [6]. NAIK et al (2013) was investigated on optimization of effective parameter of karanja biodiesel using the Taguchi method.in this study four parameter are selected molar ratio, catalyst type, catalyst concentration, reaction temperature.it is concluded that the percentage of yield of karanja biodiesel was improved using Taguchi Method [7]. PATEL et al. (2013) used Taguchi method to reduce the weight of the chassis frame of Eicher 11.10 chassis frame and FEA was performed to obtain the best solution for chassis frame [8]. PATEL et al. (2013) take up Plastic Pyrolysis Oil (PPO) blend for parametric improvement of CI engine using Taguchi method for the optimization of the Factors and experimental outcome clearly exhibit that 220 injection timing, injection pressure 200 bar, compression ratio 16 and engine load 20kg are optimum parameter setting for lowest break specific fuel consumption [8]. MODI et al. (2015) studied fuel used in diesel engine is palm seed oil and its mixture with diesel for highest BTE using Taguchi method. [9]. MAKWANA et al. (2015) studied fuel used in diesel engine is palm seed oil and its mixture with diesel for highest BTE using Taguchi method. Optimum parameter setting for highest brake thermal efficiency is $10 \mathrm{~kg}$ load, 200 bar injection pressure and $20 \%$ blend [10] PATEL et al. (2015) take up Plastic Pyrolysis Oil (PPO) blend for parametric improvement of CI engine using Taguchi method for the optimization of the Factors and experimental outcome clearly exhibit that injection pressure 200 bar, blend Biodiesel 30 and engine Load of $10 \mathrm{~kg}$ are suitable parametric Setting for less BSFC [11]. RATHOD et al. (2015) investigate parametric optimization of single cylinder compression ignition engine for mahua oil and diesel mixture for lowest BSFC using Taguchi method. [12]

\section{Methodology}

The problem of increasing demand for high efficiency of engine and low specific fuel consumption. Various technique are available for solve these problems. Optimization techniques used for engine study are Taguchi method, RSM method, nonlinear regression method, and genetic algorithm. The Taguchi method is a collection of mathematical and statistical techniques useful for the parametric optimization and analysis of problems in which a response of interest is influenced by several variables and the objective is to optimize this response.

Steps for the Experiment:

1. Identify the performance characteristics to be evaluated which are of importance to the procedure, as the case may be.

2. Design and conduct the experiments.

3. Analyze the outcomes to decide the perfect situations.

4. Run a confirmatory test using the finest situations.

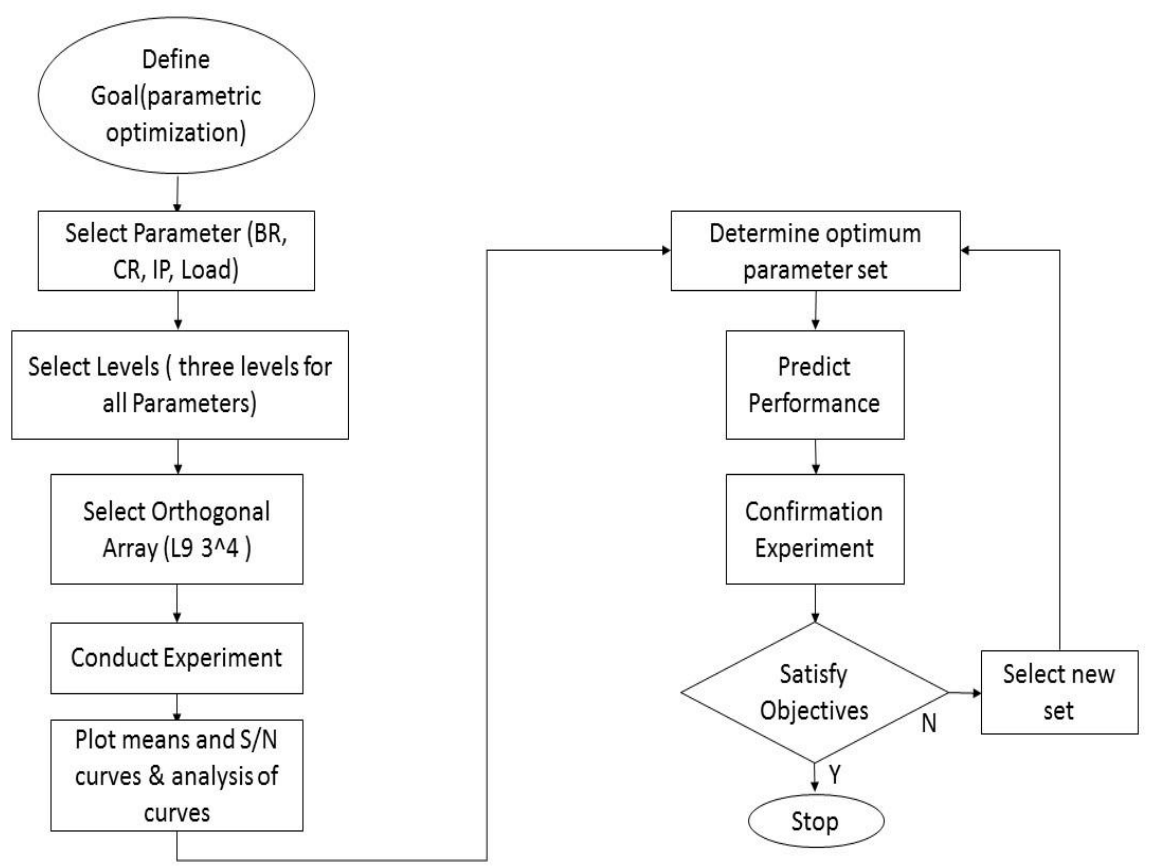

Fig.1 Flow Chart of Experiment 


\section{Factor And Levels}

Experiments are planed according to the Taguchi L9 orthogonal array for blend ratio, compression ratio, injection pressure and load. It has 9 rows corresponding to the number of testes with 4 columns at 3 levels and 4 parameters. This OA is chosen due to its capability to check the interaction among factors. Selected factors and their levels shown in table 1.

The experimental results are transferred into an $\mathrm{S} / \mathrm{N}$ ratio. There are three categories of quality characteristics in analysis S/N ratio (1) the lower the better (2) the higher the better (3) the nominal the better. The categories lower the better was used to calculated the S/N ratio for BSFC. Taguchi method is being applied to select the control factors levels (Blend ratio. Compression ratio, Injection pressure and Load) to come up with optimal response value of BSFC.

Table 1: Factors and their Levels

\begin{tabular}{|c|c|c|c|}
\hline Factor & Level 1 & Level 2 & Level 3 \\
\hline Blend & D100BO & D50B50 & D0B100 \\
\hline Compression Ratio & 18 & 16 & 14 \\
\hline Injection Pressure & 200 & 180 & 160 \\
\hline Load & 1 & 5 & 9 \\
\hline
\end{tabular}

\section{Experiment Set Up}

The setup consists of single cylinder, four stroke, multi-fuel, research engine coupled with eddy type dynamometer for loading. The mode of operation in this engine can be changed from diesel to Petrol or from Petrol to Diesel with some needed changes. In both operation modes the compression ratio can be changed without stopping the engine and no other changes needed for the geometry of combustion chamber by specially designed tilting cylinder block arrangement. Different other instruments are provided to interface are airflow, fuel flow, temperatures and load measurement devices. For cooling water and calorimeter water flow measurement Rota meter is provided. For auto start of engine a battery, starter and battery charger is provided. Analysis software Engine-soft is provided for on line performance evaluation and lab view based Engine Performance. The test engine used in this experiment is as shown in figure 2. Engine setup specifications shown in table 2.

Table 2: Engine Setup Specifications[IC Engine Manual]

\begin{tabular}{|c|c|}
\hline Engine manufacturer & Apex Innovations (Research Engine test set up) \\
\hline Software & Engine soft Engine performance analysis software \\
\hline Engine type & Single cylinder four stroke multi fuel research engine \\
\hline No. of cylinder & 1 \\
\hline Type of cooling & Water cooled \\
\hline Rated Power & $3.5 \mathrm{~kW} \mathrm{@} 1500 \mathrm{rpm}$ \\
\hline Cylinder diameter & $87.5 \mathrm{~mm}$ \\
\hline Orifice diameter & $20 \mathrm{~mm}$ \\
\hline Stroke length & $110 \mathrm{~mm}$ \\
\hline Connecting rod length & $234 \mathrm{~mm}$ \\
\hline Dynamometer & Type: eddy current, water cooled, with loading unit \\
\hline
\end{tabular}

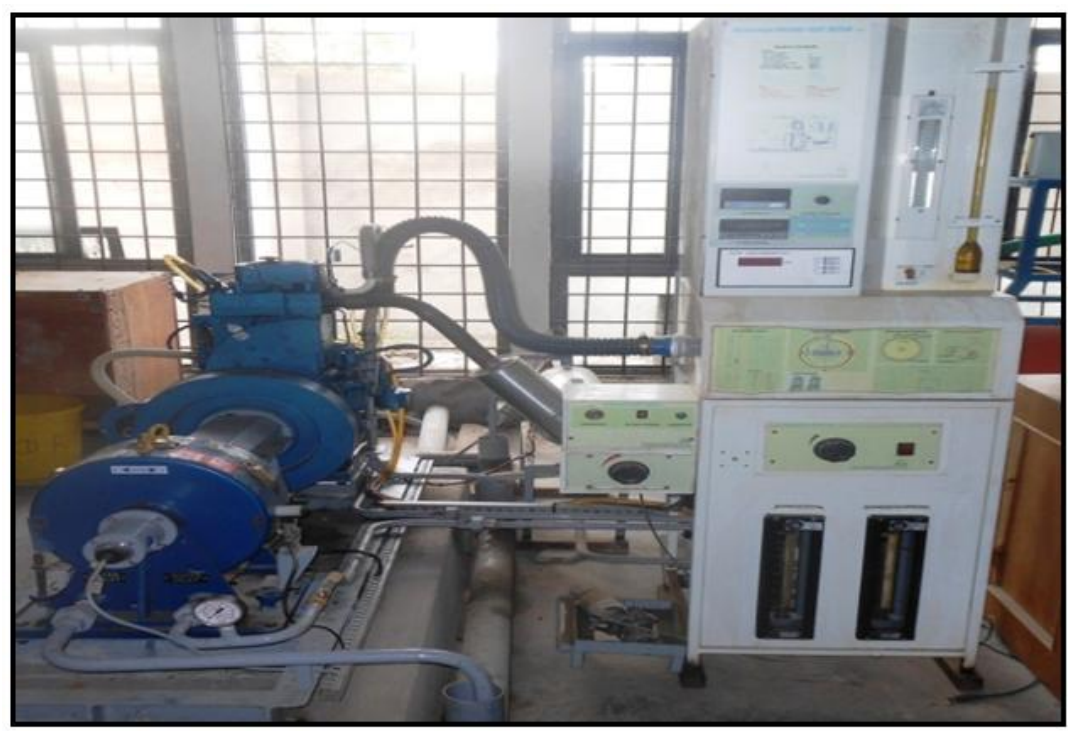

Fig. 2: Engine testing rig 


\section{Observation And Calculation}

The observed data find out by experiment on diesel engine shown in table 3. The result data for SFC obtained from the observed data is shown in table 4.

Table 3: Observation Table

\begin{tabular}{|c|c|c|c|c|c|c|c|}
\hline Sr .no & Blend (\%) & CR & $\begin{array}{c}\text { Injection Pressure } \\
(\text { Bar) }\end{array}$ & $\begin{array}{c}\text { Load } \\
(\mathbf{k g})\end{array}$ & $\begin{array}{c}\text { Speed } \\
(\mathbf{r p m})\end{array}$ & $\begin{array}{c}\text { FC } \\
(\mathbf{c c} / \mathbf{m i n})\end{array}$ & Air (mmwc) \\
\hline 1 & D100B0 & 18 & 200 & 1.07 & 1552 & 9 & 61.58 \\
\hline 2 & D100B0 & 16 & 180 & 5.15 & 1518 & 13 & 59.59 \\
\hline 3 & D100B0 & 14 & 160 & 9.09 & 1473 & 18 & 54.75 \\
\hline 4 & D50B50 & 18 & 180 & 9.02 & 1475 & 18 & 54.68 \\
\hline 5 & D50B50 & 16 & 160 & 1.05 & 1545 & 9 & 61.41 \\
\hline 6 & D50B50 & 14 & 200 & 4.89 & 1492 & 14 & 57.08 \\
\hline 7 & D0B100 & 18 & 160 & 5.01 & 1521 & 12 & 58.34 \\
\hline 8 & D0B100 & 16 & 200 & 9.05 & 1451 & 18 & 53.57 \\
\hline 9 & D0B100 & 14 & 180 & 0.94 & 1506 & 10 & 59.14 \\
\hline
\end{tabular}

Table 4: Result Table for Analysis of Brake Thermal Efficiency

\begin{tabular}{|c|c|c|c|c|c|}
\hline Sr .no & $\mathbf{F C}(\mathbf{k g} / \mathbf{h r})$ & $\mathbf{C V}(\mathbf{k J} / \mathbf{k g})$ & $\boldsymbol{\rho}(\mathbf{k g} / \mathbf{m 3})$ & $\mathbf{B P}(\mathbf{k W})$ & $\boldsymbol{\eta} \mathbf{b t h}(\mathbf{\%})$ \\
\hline 1 & 0.46 & 42850 & 833 & 0.32 & 5.84 \\
\hline 2 & 0.65 & 42850 & 833 & 1.48 & 19.12 \\
\hline 3 & 0.90 & 42850 & 833 & 2.54 & 23.71 \\
\hline 4 & 0.92 & 39392 & 856 & 2.53 & 25.13 \\
\hline 5 & 0.46 & 39392 & 856 & 0.31 & 17.64 \\
\hline 6 & 0.72 & 39392 & 856 & 1.39 & 22.93 \\
\hline 7 & 0.63 & 36120 & 880 & 1.45 & 2.49 \\
\hline 8 & 0.95 & 36120 & 880 & 8.27 & 5.07 \\
\hline 9 & 0.53 & 36120 & 880 & 0.27 & \\
\hline
\end{tabular}

\section{Result And Discussion}

The results of BTE are analyzed using Minitab 17. Minitab offers four types of designed experiments: factorial, response surface, mixture, and Taguchi (robust). The steps follows in Minitab to create, analyses, and graph an experimental design are similar for all design types. After conducting the analysis and entering the results, Minitab provides several analytical and graphing tools to help understand the results. The $\mathrm{S} / \mathrm{N}$ ratio for optimal BTE are coming under "Higher-is-better" characteristic, which can be calculated as logarithmic transformation of the loss function.

In the experiment, four parameters is consider like as Blend ratio, CR, Injection pressure, Load. Main Effects Plot for Mean data and S/N ratio data are shown in Fig. 3 and 4 that shows optimal results of BTE. From figure-3, mean is an average measure of reading taken for specific variables. The mean value is the maximum (18.04) for D0B100 blend and minimum (0.793) for D50B50 blend. The mean value is the maximum (0.943) for 14 compression ratio and minimum (0.753) for 18 compression ratio. The mean value is the maximum (0.923) for 180 bar injection pressure and minimum (0.76) for 160 bar injection pressure. The mean value is the maximum (1.63) for $1 \mathrm{~kg}$ engine load and minimum (0.366) for $9 \mathrm{~kg}$ engine load. As portrayed in figure-4 the response curve for $\mathrm{S} / \mathrm{N}$ ratio, better performance at set $0 \%$ blend ratio, compression ratio 18 , engine load $9 \mathrm{~kg}$ and injection pressure 160 bar which is the optimum parameter setting for highest BTE as shown in table 5.

Taguchi Analysis for BTE by Using Minitab Software

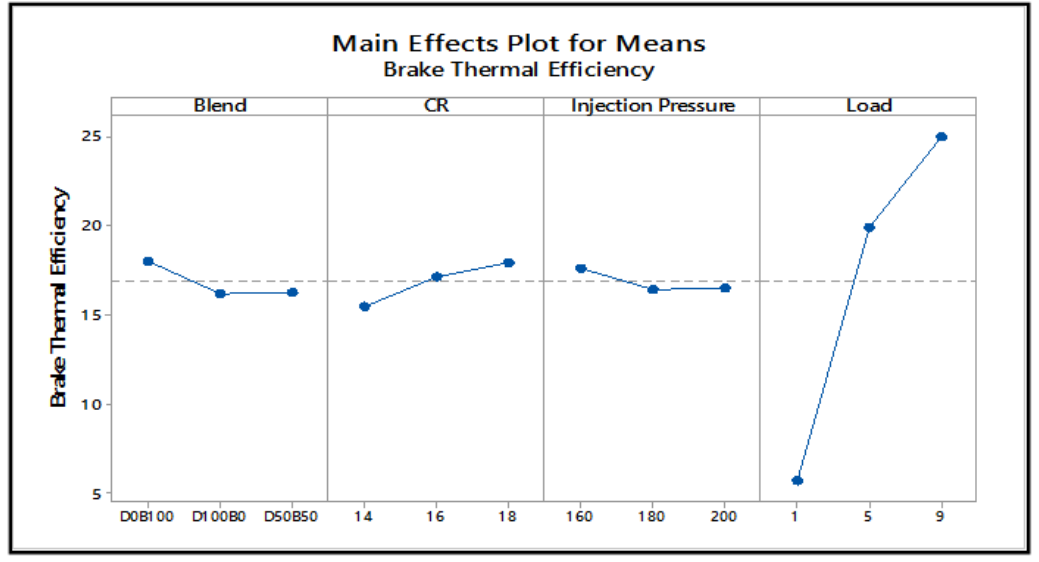

Figure 3: Main Effects Plot for Means of BTE 


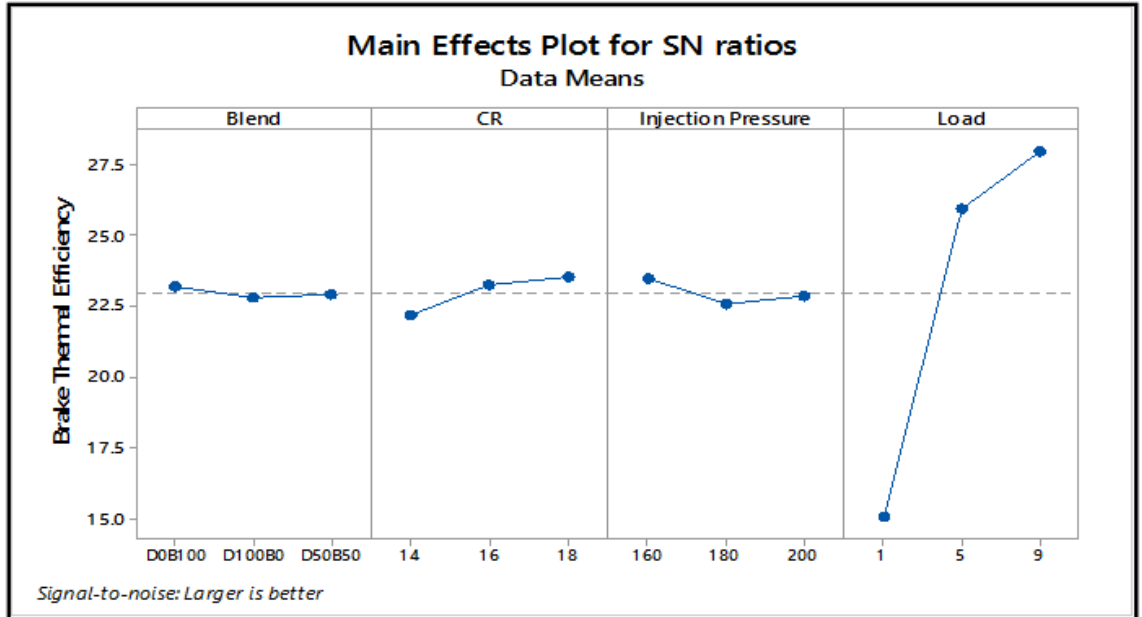

Figure 4: Main Effects Plot for S/N ratio of BTE

Table 5: Optimize set of parameter for BTE.

\begin{tabular}{|c|c|c|c|c|c|}
\hline Blend Ratio (\%) & CR & Injection Pressure (Bar) & Load (kg) & BTE (\%) & S/N ratio \\
\hline D0B100 & 18 & 160 & 9 & 28.02 & 29.2328 \\
\hline
\end{tabular}

Experiment has done for above set of parameter gives performance given below. This experimental value is nearer our predicted value. So, that our analysis going to a right way.

Table 6: Validation Results for BTE.

\begin{tabular}{|c|c|}
\hline \multicolumn{2}{|c|}{ Validation Results for Brake thermal Efficiency } \\
\hline Predicted Value & Experimental Value \\
\hline 28.02 & 27.06 \\
\hline
\end{tabular}

\section{Conclusion}

The Taguchi method was found to be an efficient technique for quantifying the effect of control parameters.

Result discuss below,

- For BTE diesel Fuel, D0B100 blend ratio, Engine Load (9 kg), Injection pressure (160) and Compression ratio (18) which are optimum parameter setting for highest Brake Thermal Efficiency.

- Engine performance is mostly influenced by engine load (maximum Delta-12.88 \& lowest Rank-1) and blend ratio is least effective (minimum Delta-0.40 \& highest Rank-4) for Brake Thermal Efficiency.

- $\quad$ This experimental value $27.07 \mathrm{~kg} / \mathrm{kWh}$ was nearer our predicted value $28.02 \mathrm{~kg} / \mathrm{kWh}$.

\section{References}

[1] Nataraj, M., Arunachalam, V. P., \& Dhandapani, N. (2005). Optimizing diesel engine parameters for low emissions using Taguchi method : variation risk analysis approach — Part I, 12(June), 169-181.

[2] Hulwan, joshi, a. (2010). Study on properties improvement and performance benefit of diesel-ethanol-biodiesel blends with higher percentage of ethanol in a multicylinder idi diesel engine. International journal of advance engineering technology, vol.I $\mid$ (sept 2010).

[3] Karnwal, A., Hasan, M. M., Kumar, N., Siddiquee, A. N., \& Khan, Z. A. (2010). Paper ID : 20100142 Optimization of Diesel Engine Performance Parameters by Applying Taguchi Method and Grey Relational Analysis, (November), 1-6.

[4] Joshi, D. H., \& Patel, T. M. (2012). Parametric optimization of single cylinder diesel engine for pyrolysis oil \& diesel blend for mechanical efficiency using Taguchi method, 1(4) | page1-6.

[5] Sivaramakrishnan, K., \& Ravikumar, P. (2012). PERFORMANCE OPTIMIZATION OF KARANJA BIODIESEL ENGINE, 7(4), 506-516.

[6] Dhar, A., \& Agarwal, A. K. (2015). Effect of Karanja biodiesel blends on particulate emissions from a transportation engine. FUEL, 141, 154-163. https://doi.org/10.1016/j.fuel.2014.09.124.

[7] P L Naik M, D. C. K. (2013). Optimization of Effective Parameters of Pongamia Pinnata (Karanja) Biodiesel Using Taguchi Method, 3(4), 701-706.

[8] Patel, T. M., \& Bhatt, N. M. (2015). FEM based Taguchi method to reduce the Automobile Structural Member Weight, 2-11.

[9] Patel Pragna R., Prof. Tushar M. Patel, Prof. Gaurav R. Rathod "Parametric Optimization of Single Cylinder Diesel Engine for Specific Fuel Consumption Using Plastic Pyrolysis Oil as a Blend" Volume 5 | Issue $4 \mid 2013$ | Page 03.

[10] Modi, M. A., Patel, T. M., \& Rathod, G. P. (2014). Parametric Optimization Of Single Cylinder Diesel Engine For Palm Seed Oil \& Diesel Blend For Brake Thermal Efficiency Using Taguchi Method, 4(5), 49-54.

[11] Patel, K. B., Patel, T. M., \& Patel, S. C. (2013). Parametric Optimization of Single Cylinder Diesel Engine for Pyrolysis Oil and Diesel Blend for Specific Fuel Consumption Using Taguchi Method, 6(1), 83-88.

[12] Rathod, N. H., Rathod, G. R., \& Patel, T. M. (2015). Parametric optimization of single cylinder CI engine for specific fuel consumption using mahua oil blend, 12(2), 28-33. https://doi.org/10.9790/1684-12242833. 